\title{
A ESPIRITUALIDADE NO CONTEXTO DA EXPERIÊNCIA DO PACIENTE CIRÚRGICO *
}

Denise Suzanna Siebert Hense **

\begin{abstract}
RESUMO - Este artigo apresenta os resultados de uma pesquisa qualitativa que adotou a Metodologia da Teoria Fundamentada nos Dados para estudar a espiritualidade e a experiência do paciente cirúrgico. Enfoca a subjetividade e o significado para o paciente da vivência de ter que ser operado, destacando o papel e a participação que nela tem a sua espiritualidade. Aponta algumas implicações para a prática da enfermagem na assistência espiritual ao paciente cirúrgico.
\end{abstract}

\begin{abstract}
This article presents the results of a qualitative research which adopted the Grounded Theory Methodology to study the surgical patient's spirituality and experience. It focuses on the subjectivity and the meaning of the surgical experience for the patient of having to submit to a surgery, while distinguishing the role and the participation of his spirituality in the experience. It points out same implications for surgical nursing in spiritual assistance to the patient.
\end{abstract}

\section{INTRODUC̣ÃO}

() estudo da experiência do paciente cirúrgico e de sua espiritualidade surgiu a partir da preocupação com a assistência de enfermagem adequada a ser prestada nesta situação de vida, com especial destaque ao que se refere à assistência espiritual. Lendo sobre o assunto percebe-se que muito pouco tem sido escrito sobre a espiritualidade do paciente hospitalizado. Os poucos estudos realizados verificam os aspectos relativos a ela apenas num momento de todo o período de hospitalização, não se preocuparam em ver como ela evoluia desde a internação até a alta hospitalar. Nos questionários e entrevistas utilizados predominavam questões fechadas elaboradas de acorào com um roteiro préestabelecido conforme as idéias que preliminarmente 0 autor já tinha. Isso pode ter limitado as respostas dos pacientes que participaram dos estudos, além de dificultar a identificação de algo novo quanto à espiritualidade, algo que até agora não fora percebido.

\footnotetext{
* Resumo da Tese de mestrado apresentada à Escola de Enferma. gem da UFSC:

* (iraduada em Enfermagem pela UFSC, Licenciadla em Enfermagem pela UFRGS, Mestre em Ciência da Enfermagem pela [IFSC.
}

A consciência dessa situação, somada ao interesse pelos aspectos relativos à espiritualidade, é que me levaram a tentar outro tipo de estudo. Um estudo onde iria além de entrevistar ou solicitar que o paciente respondesse um questionário, conversar e conviver como ele e com a equipe que $o$ assiste no transcorrer do período de hospitalização. Meu desejo era ouvir o que ele tinha a me contar de sua experiência como paciente cirúrgico e de sua espiritualidade naquela situação de vida. Queria estar aberta para eventuais novos aspectos que pudessem ser mencionados e que, até então, não haviam sido identificados.

\section{METODOLOGIA}

Para ser coerente com a proposta do estudo, a metodologia a ser utilizada só poderia ser qualitativa, que defere em vários pontos da metodologia quantitativa, tradicional e amplamente utilizada nos estudos científicos. Uma metodologia qualitativa prioriza a convivência com as pessoas que participam do estudo, para que se possa apreender o máximo de sua experiência, dos seus sentimentos, de suas opiniões e dos fatos envolvidos. É importante sentir e viver com elas sem no entanto perder a visão objetiva de pesquisador. Uma pesquisa qualitativa não utiliza caracteristicamente a 
análise estatística dos dados obtidos junto aos informantes como é o caso da metodologia quantitativa. A análise é muito mais um processo mental pelo qual passa o pesquisador ao coletar e refletir sobre os dados ao comparar entre si todas as informações coletadas.

Os dados do presente estudo foram coletados junto a pacientes cirúrgicos previdenciários e particulares, submetidos à cirurgias consideradas necessárias, de pequeno e médio portes, num hospital de uma cidade de Santa Catarina nos meses de abril a dezembro de 1985. Foram selecionados três diferentes grupos de pacientes, que juntos totalizaram uma amostra de 31 pacientes. Para coletar os dados foi utilizada a observação participante, desenvolvida através de técnicas como a observação, a entrevista com o paciente e equipe de saúde, participação na assistência e consulta ao prontuário. A análise dos dados, que se deu de forma integrada e simultânea com a coleta dos dados, foi feita através da constante comparação dos dados para que assim se pudesse ir gradativamente construindo um esquema que representasse a experiência e a espiritualidade do tipo de pacientes em estudo.

\section{RESULTADOS}

() que é a espiritualidade do paciente cirúrgico? Coıno ele mesmo a entende? Como ele a vive na situação de doença, hospitalização e cirurgia? Qual seu papel dentro da experiência vivida?

Antes de responder a estas perguntas norteadoras são necessárias algumas considerações. São três os aspectos experimentados na etapa preliminar do estudo e que gostaria de destacar. Primeiro: há diferentes maneiras de entender-se o que seja "espiritualidade". A idéia a respeito dela varia de pessoa para pessoa. Algumas pessoas, por exemplo, a entendem como transcendência ou energia; outros como princípio de vida ou código de ética, filosófica ou moral; outros ainda como questionamentos e problemáticas que envolvem a existência, a natureza, o destino, a vida e a morte; há também os que se referem a ela como sistema de crenças ou crença no sobrenatural. Para os cristãos, ela está centralizada em Deus, Jesus Cristo e no Espírito Santo. Segundo: a espiritualidade não envolve apenas o que pensamos a seu respeito, mas principalmente como a vivemos. É na nossa esperiência diária que realmente revela-se o que ela significa para nós, pois nem sempre o que pensamos evidencia-se na prática. Terceiro: é impossível separar a espiritualidade dos outros aspectos que formam a nossa vida, das nossas experiências diárias e da situação que estamos vivenciando. Temos que entendê-la dentro deste contexto.

Ao iniciar o estudo pensava em estudar somente a espiritualidade. No entanto ao começar a coletar os dados percebi que não poderia fazê-lo sem entender primeiro o que significa para o paciente estar doente, ser hospitalizado e ser operado. Percebi que, apesar de sempre ter falado e pensado na espiritualidade como algo ligado à nossa experiência diaŕia, na hora de estudá-la eu estava querendo separá-la da experiência vivida pelo paciente naquela situação. Vi que para entender verdadeiramente o que significa a espiritualidade para o paciente teria que considerar seu contexto de vida, para assim poder ir além do que ele fala sobre ela, mas verificar também como ele a vive. Tive também que reconhecer que, apesar de querer estar aberta para o que o paciente me dizia, eu também tinha certas idéias preliminares quanto à espiritualidade - sou cristã e não poderia deixar de sê-lo. Tinha que, no entanto, tomar cuidado para não inferir ou interpretar as informaçòes que (oleta junto ao paciente. Não era meu papel julgá-lo, mas sim entendê-lo. Por isso, também aqui neste texto, é necessário que primeiro entendamos o que é ser um paciente cirúrgico, como ele mesmo vive e sente a experiência de doença, hospitalização e cirurgia.

Para o paciente esta é uma situação que se caracteriza fortemente pela sensação de obrigatoriedade, de pressão ou de sentir-se forçado. Ele não deseja operar, ele "Tem que" operar. Por isso, pode-se dizer que no seu todo essa é uma situação percebida como "Tendo que (Operar". Isso é verdade desde o momento em que surgem as manifestaçòes de alteraçōes na saúde até a alt a hospitalar, passando por experiência como "ter que" ir ao médico, "ter que" internar e "ter que" submeter-se à cirurgia. (O "Tendo que ()perar-se" expressa a experiência global do paciente e envolve três diferentes vivências. Primeiro: as vivências físicas, (como a dor, as náuseas, a falta de apetite, a indisposição física que em maior ou menor grau "tem que" ser vividas pelo paciente. Segundo: as vivências consideradas mentais ou racionais e que envolvem tudo o que o) paciente pensa ou faz para diminuir ou acabar com os problemas ou dificuldades encontradas. Terceiro: as vivências relacionadas mais especificamente com os sentimentos, emoções e sensações experimentadas pelo paciente, como é o caso do medo, da agonia, da preocupação e do nervosismo.

"Tendo que Operar-se" é sem dúvida uma experiência difícil e desagradável para o paciente. Percebese, no entanto, que no seu transcurso ele utiliza maneiras de aliviar a dificuldade presente. São recursos que amenizam a experiência para ele, mas que nunca chegam a contrabalançá-la. São três ao todo. Primeiro: buscar e encontrar uma explicação para o fato da doença e a cirurgia terem acontecido com ele. Geralmente, conhecer os fatores que levaram ao surgimento da doença e encontrar um significado transcendental na experiência o deixa mais tranqüilo. Segundo: confiar na equipe de saúde, em si e principalmente em I)eus. A confiança gera nele uma certa sensação de c'erteza e segurança. Terceiro: ter a ajuda das pessoas e de Ieus. As pessoas a sua volta e Deus podem dar-lhe auxílio, amparo, proteção e força.

Agora, depois de ter uma idéia de como o paciente vive o fato de estar doente, de "ter que" ser hospi- 
talizado e operado, é que se pode explorar mais de perto sua espiritualidade. A idéia que o paciente, de forma geral, tem de sua espiritualidade, é que ela é algo estreitamente ligado à sua vida religiosa. É essencialmente ali que ela se manifesta. Convivendo com ele, no entanto, percebe-se algo mais que isso. Vale ressaltar que os pacientes que participaram do estudo eram ou católicos ou evangélicos e, em maior ou menor grau, tinham algum tipo de prática religiosa. Não eram diferentes da maioria dos brasileiros.

Observando, conversando e refletindo sobre a espiritualidade do paciente cirúrgico percebe-se que o aspecto mais significativo que transparece é a busca e o "reconhecimento de um ser superior". É basicamente dessa forma que ele vive sua espiritualidade desde a manif estação da alteração na saúde até a alta hospitalar. É bastante comum ele buscar uma maior proximidade com Deus, com Jesus, com Maria e com os Santos. Especialmente Deus tende a ser percebido como tendo o poder supremo. Muitas vezes um último recurso, alguém que ainda pode fazer algo quando ninguém mais pode.

0 "reconhecimento de um ser superior" ameniza a experiência para o paciente cirúrgico já que Deus geralmente está de alguma forma associado à explicação encontrada para o fato de estar vivendo tal situação, é nele também que ele deposita sua maior confiança e encontra o apoio ou ajuda espiritual desejada. () "reconhecimento de um ser superior' expressa o todo do que é para o paciente cirúrgico sua espiritualidade e envolve quantro aspectos dist intos. () Primeiro: já mencionado, é aquele que se refere ao aspecto mais of icial, tradicional ou institucionalizado, sua "afiliaçào religiosa”. Inclui sua denominação religiosa; seus hábitos religiosos ('omo ler a Bíblia ir à missa ou ao culto, fazer novena, rezar e confessar; e os relacionamentos eclesiásticos que ('onstumeiramente são mantidos com o padre/pastor, ('om amigos da igreja e com a igreja em si. Segundo: o "reconhecimento de um ser superior" também pode ser indentificado noutro aspecto, na bus('a de um signific'ado' para a doença, cirurgia e sofrimento. Pensar que a doença é algo que pode levar para mais perto Deus, que ela é uma forma de Deus nos chamar, que "ele permite a doença e a cirurgia para que nos tornemos mais crentes", são idéias que tranqüilizam o paciente ao lhe dar uma perspectiva transcendental para o que está acoritecendo. O Terceiro aspecto refere-se ao "apoio e a retaguarda espiritual" desejados e experimentados pelo paciente. Deus, Jesus, Maria e os Santossão para ele uma importante fonte de auxílio, proteção e força. Envolve os pedidos de cura e sucesso na operação; a força obtida de símbolos religiosos como um crucifixo; o preparo interior do paciente expresso nas novenas, na confissão, na leitura da Bíblia, na Comunhão ou Santa Ceia. Também inclui as condições que ele recebe de Deus para enfrentar as dificuldades, como coragem e paciência. Deus também pode intervir acabando com a dificuldade, co- mo por exemplo, acabando com a dor sentida. O auxílio espiritual também pode ser recebido de outras pessoas através de suas orações e seus conselhos. () quarto e último aspecto identificado como parte de "reconhecimento de um ser superior' está relacionado com a "confiança" que ele tem nesse ser superior. Ela engloba a constante lembrança de Deus, a crença ou fé nele, o apego a Deus, Jesus, Maria e aos Santos, a entrega a Deus e aceitação de sua vontade como a melhor.

() "reconhecimento de um ser superior" é algo que está presente no transcorrer de toda a experiência do paciente cirúrgico, desde que ele perceba a alteração na sua saúde até a alta hospitalar. É necessário, no entanto, ressaltar que cada um dos quatro aspectos mencionados tende a se evidenciar em diferentes momentos da experiência. ()s aspectos relacionados a "afiliação religiosa" tendem a estar mais evidentes quando ele ainda está em casa. É quando seus hábitos religiosos e relacionamentos eclesiásticos se intensificam, pois, com a internação estes são muitas vezes dificultados. Os aspectos relacionados a "busca de significado", "apoio ou retaguarda espiritual" e "confiança", por sua vez tendem a se evidenciar desde o momento em que ele recebe a noticia da necessidade da cirurgia até o momento de sua realização. É quando espera ser operado que ele mais busca o apoio de um ser superior. É nessa época que ele mais se apega à fé em Deus, ao auxílio, à força e à proteção que Deus pode lhe dar ao significado nele encontrado para o fato de estar vivendo sua situação difícil.

Além disto é necessário ressaltar que a intensidade com que cada paciente experimenta cada um dos aspectos mensionados pode variar. Um paciente pode, por exemplo, expressar o "reconhecimento de um ser superior" mais através da "afiliação religiosa", enquanto outro, através do "apoio ou retaguarda espiritual". Alguns demonstram claramente o vínculo e apego a I)eus. ()utros, apesar de lembrarem de I)eus e rezarem demonstram uma aparente indiferença fazendo brin(adeiras sobre a morte e sobre I)eus, ou então, mostrando-se seguros do sucesso da cirurgia.

Percebe-se que o "reconhecimento de um ser superior" é algo que tende a se tornar mais forte na dificuldade, nos momentos em que o paciente sente-se com menos poder e em maior risco de vida como quando no centro cirúrgico. Paralelamente também nota-se que esse reconhecimento está relacionado à experiência passada do paciente. () tipo de vínculo que ele mantinha com Deus no passado, antes de adoecer, influencia sua experiência com Deus quando doente e hospitalizado. O paciente que costumava manter um relacionamento pessoal e constante com Deus tende a encontrar nele uma maior confiança, ajuda e sentido nesta situação.

\section{IMPLICAC̣ÕES}

Mas... o que tudo isto tem a ver com a nossa prática na assistência ao paciente? Bem, primeiramente esta 
é a maneira de ele viver e pensar sua espiritualidade. Talvez diferente da maneira como nós vivamos a nossa, ou da maneira como nós acreditamos que ele viva a dele. Por isso, se quizermos auxiliar o paciente e assistí-lo de forma integral, sem excluir sua espiritualidade, é necessário que nos aproximemos dele considerando que sua espiritualidade se manifesta na forma do "reconhecimento de um ser superior" e dos quatro aspectos que o compoem.

Vamos refletir agora especificamente nas aplicações que o conhecimento gerado pelo presente estudo pode ter na prática da enfermagem. Apesar de caber ao capelão e ao ministro religioso a assistência espiritual especializada, o enfermeiro não está isento de atuar junto com eles num trabalho integrado, incluindo a espiritualidade do paciente na utilização e desenvolvimento da metodologia de assistência adotada. Dentro dessa perspectiva sugere-se que:

a) no histórico de enfermagem seja considerado o levantamento dos dados no que se refere aos quatro componentes do "reconhecimento de um ser superior" (QUADRO 1);

b) no transcurso da experiência do paciente cirúrgico, desde a manifestação da alteração na saúde até a alta hospitalar, seja considerado que o "reconhecimento de um ser superior" 'apresenta mudanças no tempo, devendo-se por isso, a cada momento, prestar especial atenção aos aspectos que naquela ocasião tendem a se evidenciar;

c) seja verificado como o paciente está vivendo toda a situação percebida como "Tendo que Operar-se" e os meios utilizados para amenizá-la;

d) o planejamento da assistência espiritual seja flexível e inclua metas que direcionem a conduta da equipe de enfermagem mas oportunidades de contato e nos momentos de crise, para garantir a continuidacle da assistencia;

e) na implementação seja considerado que cada paciente é único e que por isso ações esteriotipadas devem ser evitadas, onde a oração, a Bíblia e o encaminhamento ao ministro religioso devem ocorrer de acordo com a sit uaçāo pessoal de cada paciente; e que

f) o enfermeiro avalie e tenha sempre em mente as características de sua própria espiritualidade para evitar confundí-la com a do paciente a provocar distorções na avaliação e no planejamento da assistência a ser prestada ao paciente.
QUADRO 1 aspectos a considerar no levantamento de dados relacionados à espiritualidade do paciente cirúrgico que submete-se à cirurgias necessárias de pequeno e médio portes.

\section{ESPIRITUALIDADE: "Reconhecimento de um Ser Superior"}

“Afiliação Religiosa”: denominação religiosa, história religiosa e práticas consideradas importantes, evidência de alguma prática religiosa, relacionamentos eclesiásticos considerados importantes, significado da religião, significado e importãncia de Deus, Jesus, Maria e dos Santos.

“Busca de um Significado": participação que a religião, Deus ou outro ser considerado superior tem no significado da doença, cirurgia, sof rimento, objetivo da vida, desenvolvimento de suas atividades e comportamento; influência principal de Deus na vida.

“Apoio e Retaguarda Espiritual": relacionamento que mantêm com Deus, cuidado e proteção sentidos, o que o faz sentir cuidado por Deus, apoio espiritual dado por outros, visita do padre/pastor/leigos.

"Confiança”: lembrança de Deus, características da crença em Deus ou em outro ser considerado superior, apego a Deus, Jesus, Maria e aos Santos, maneira e a quem se entrega quando em dificuldade.

\section{Sintese:}

- significado da prática religiosa;

- conceito de Deus e/ou de outro ser considerado superior;

- influência e características gerais da participação de Deus ou de outro ser considerado superior na explicação dada para a situação vivida, na ajuda recebida e na confiança sentida. 